\title{
LOS ROMANCES DE LORENZO DE SEPÚLVEDA: DE LAS EDICIONES ANTUERPIENSES A LA PRINCEPS
}

\author{
THE ROMANCES OF LORENZO DE SEPÚLVEDA: \\ FROM THE ANTWERPIAN EDITIONS TO THE PRINCEPS
}

\author{
MARIO GARVIN \\ Universität Konstanz \\ mario.garvin@uni-konstanz.de
}

\begin{abstract}
Resumen: Las dos ediciones más antiguas conservadas de los Romances de Lorenzo de Sepúlveda (Steelsio, 1551 y Nucio, s.a., ambas en Amberes) guardan entre sí una compleja relación. Según se cree, Nucio copiaría a Steelsio, cuya edición provendría directamente de la princeps. El presente trabajo argumenta que la edición de Nucio conservada procedería de una edición perdida, del mismo impresor, que copiaría la princeps y de la cual derivaría también la edición de Steelsio. De admitirse esta tesis, habría entonces que modificar las bases sobre las que se historia el llamado romancero erudito, que comienza con esta obra.

Palabras clave. Romancero; romancero erudito; crítica textual; Mar-

tín Nucio; Lorenzo de Sepúlveda.
\end{abstract}

Abstract: The two oldest preserved editions of the Romances of Lorenzo de Sepúlveda share a complex relationship. The common opinion is that Steelsio's edition stems directly from the princeps while Nucio simply copies Steelsio. This paper argues that Nucio's preserved editions actually derive from an older, lost edition of his own, which stems from the princeps and is also the source of Steelsio's edition. If this is so, then it will be necessary to modify the bases determining the history of the so-called "Romancero erudite", which begins with this work.

Keywords: Romancero; romancero erudito; critical scholarship; Mar-

tin Nutius; Lorenzo de Sepúlveda.

Recepción: 14 de noviembre de 2016; aceptación: 20 de febrero de 2017.

D.R. (C) 2018. Nueva Revista de Filología Hispánica Licencia Creative Commons Attribution-NonCommercial (CC BY-NC) 4.0 International 
INTRODUCCIÓN: EL PROBLEMA*

La primera edición de los Romances de Lorenzo de Sepúlveda probablemente se haya perdido para siempre. Todo lo que sabemos de este autor ${ }^{1}$-con quien comienza, según común acuerdo, el llamado romancero erudito-, así como de su obra, debe partir por tanto de los textos existentes. Esa tarea, sin embargo, no resulta nada sencilla, pues la relación entre las ediciones conservadas no ha sido aún aclarada satisfactoriamente.

Dos son las ediciones más antiguas de las que tenemos noticia: ambas proceden de talleres antuerpienses; una se imprimió en el taller de Juan Steelsio en 1551 y la otra salió sin fechar de las prensas de Martín Nucio en la misma ciudad. Desde un punto de vista material, ambas ediciones son muy semejantes: tienen una extensión casi idéntica -263ff. de Steelsio, por 276 de Nucio- y el mismo formato, en dozavo. Comparten también, además de estos rasgos, un prólogo del autor, Lorenzo de Sepúlveda, donde éste comenta los motivos que le llevaron a componer sus romances. Y, sin embargo, son dos ediciones notablemente distintas.

Una de las pocas afirmaciones rotundas que pueden hacerse es que ninguna de las dos ediciones conservadas reproduce fielmente la princeps. La de Steelsio, además del mencionado prólogo de Sepúlveda, contiene 149 textos, algunos exclusivos, según indica el impresor-editor: "Añadiose el romance de la conquista de la ciudad de África en Beruería, en el año de M.D.L. y otros diuersos, como por la Tabla parece" ${ }^{2}$. La de Nucio contiene un total de 162 textos y, al igual que la edición de Steelsio, muchos de ellos son exclusivos. A diferencia de su colega, Nucio escri-

* Este trabajo se enmarca en el proyecto Cancionero, Romancero e Imprenta del grupo CIM (www.cancioneros.org), financiado por el Ministerio de Economía y Competitividad (FFI2014-52266).

${ }^{1}$ El primero en proponer la identificación de este autor con el Sepúlveda de la Comedia erudita fue Menéndez Pelayo (1944, t. 6, pp. 210 y 249, y t. 7, pp. 91-96). R. Menéndez Pidal (1953, t. 2, pp. 111-112) adoptó estos datos y los repitió. ANTONio Rodríguez-MoÑino (1967, pp. 27-28) se muestra mucho más cauto, al poner en duda esta atribución. Solamente un buen trabajo de archivo podría resolver la cuestión de modo definitivo.

${ }^{2}$ Hace ya más de un siglo (en 1903) apareció una edición facsímil de los Romances nueuamente sacados de historias antiguas dela crónica de España compuestos por Lorenço de Sepúlveda. Añadiose el Romance dela conquista dela ciudad de África en Beruería, enel año M.D.L. y otros diuersos, como por la Tabla parece, 1551. Hoy la edición de Steelsio es fácilmente accesible en Google Books. 
be un prólogo en el que afirma haber añadido textos "assí de la sagrada escritura como de las historias de España”, que luego marca en la tabla con un asterisco, de modo que podamos saber cuáles son los textos que ha incorporado. En total, ambas ediciones comparten la nada despreciable cifra de 140 textos.

El orden de las composiciones es muy distinto en una y otra edición. De Nucio sabemos que reordenó su fuente ("vn libro impresso... en Seuilla") para que, según escribe en el prólogo,

se pusiessen algunos romances no como estauan sino como deuen, porque auiendo en él muchos que tratan de vna mesma persona no me pareció justo que estuuiessen derramados por el libro como estauan, mas que se juntassen todos en vno, porque desta manera la historia dellos será más clara y al letor será más apazible (f. $2 \mathrm{v}$ ).

La edición de Steelsio, en cambio, no menciona en ningún lugar que se hayan hecho modificaciones de ese tipo. Esta última particularidad se ha antojado decisiva para creer que la edición de Steelsio podría estar reproduciendo la princeps de manera más o menos fiel -si dejamos de lado los añadidos-, mientras que la de Nucio reproduciría -reordenando, según hemos visto- los materiales de Steelsio. Esta teoría de dependencia es la que defiende Antonio Rodríguez-Moñino (1969, p. 102). En su opinión:

Nucio se había adelantado con el Cancionero de romances s.a. descubriendo así un filón por nadie explotado antes; Steelsio aguardaba la hora de la revancha y creyó encontrarla al recibir de Sevilla tal vez el primer ejemplar llegado a Anvers de los Romances sacados de historias antiguas de la crónica de España por Lorenzo de Sepúlveda, el cual fue inmediatamente a manos de los cajistas y sin poner preámbulo nuevo ni cosa que lo valiera, salió a la calle bajo su enseña editorial.

Para hacer esta afirmación, el erudito extremeño se basa en la lectura de unas palabras de Nucio en el prólogo, donde nos habla sobre sus motivaciones editoriales para sacar el libro. Escribe allí:

Como yo auía tomado los años passados el trabajo de juntar todos los Romances viejos (que auía podido hallar) en vn libro pequeño y de poco precio, con protestación hecha en el prólogo dél, que 
yo auía hecho en él no lo que deuía sino lo que podía, veo que he abierto camino a que otros haga $n$ lo mesmo, porque avnque es cosa que fácilmente se pudo començar, no será possible poderse acabar, ni avn demediar por ser las materias difere $n$ tes, y en que cada día se puede añadir, y componer otros de nuevo. Agora ha venido a mis manos vn libro nueuamente impresso en Seuilla, el qual me pareció imprimir por seguir el intento con que esto comencé (ff. 2v-3r).

Para Rodríguez-Moñino (1967, p. 26) resulta evidente que estas palabras de Nucio "acusan el golpe editorial recibido" y también que con ellas reclama "para sí la iniciativa en la colecta”. De este modo, la edición de Steelsio sería, según él-salvando los nueve textos añadidos que ya hemos mencionado-, "fiel reflejo y copia de la original hoy perdida" (p. 11), una princeps que Rodríguez-Moñino se atreve incluso a datar e identificar: no cabe duda, escribe, de "que Sepúlveda imprimió sus Romances en Sevilla, antes de 1550, acaso en las prensas de Juan de León, que había dado al público algunos volúmenes de música y poesía interesantes y de contenido más o menos relacionado con nuestro tema" (p. 10).

\section{Problemas de Dependencia}

Una relación lineal princeps $>$ Steelsio $>$ Nucio, tal y como la plantea Rodríguez-Moñino, no aclara los numerosos problemas que se derivan de una comparación minuciosa de ambas ediciones. Encontramos, en primer lugar, un detalle harto significativo que, sorprendentemente, han pasado por alto tanto Rodríguez-Moñino como la crítica posterior, pero que, según creo, nos ofrece un argumento fundamental en favor de una relación distinta a la por él propuesta.

Como se ha visto, Nucio, en su prólogo, escribe que acaba de llegar a sus manos "vn libro nueuamente impresso en Seuilla, el qual me pareció imprimir por seguir el intento con que esto comencé" (f. 3r). Dos detalles son aquí especialmente relevantes: la mención de ese "libro nueuamente impresso en Seuilla" y el intento al que hace referencia Nucio. Comencemos por el libro. En la edición de Steelsio no hay alusión alguna a la supuesta procedencia sevillana de la princeps. Es, lo repito para subrayar la importancia del dato, información exclusiva de la edición de Nucio. Esto abre varias posibilidades. Si, como cree Rodríguez- 
Moñino (1967), Steelsio fue quien recibió "el primer ejemplar llegado a Anvers" de la princepsy Nucio está utilizando la edición de Steelsio, esa mención a Sevilla se vuelve difícil de explicar. Podría pensarse, como primera posibilidad, que Nucio, simple y llanamente, se lo estuviera inventando, suposición por completo descartable por incongruente y falta de motivación alguna; como segunda, que Nucio estuviera deduciendo el dato de una mención del propio Sepúlveda, quien en su prólogo se refiere a Sevilla como "mi patria natural"; o, como tercera, finalmente, que Steelsio fuera -tal y como suponía Rodríguez-Moñino- quien recibió "el primer ejemplar llegado a Anvers" de la princeps y que Nucio, que sin duda tenía contactos suficientes para enterarse de la procedencia de la obra en que se basaba su competidor, aun cuando éste no la mencionase, se apropiara del dato y lo pusiera en su propia edición. Pero cabe, por supuesto, otra posibilidad: que Nucio no estuviera copiando la edición de Steelsio. Y precisamente la referencia de Nucio al "intento con que esto comencé" hace que me decante por esta última.

Rodríguez-Moñino, según se ha revisado antes, basaba su teoría en una interpretación del prólogo de Nucio como ataque velado a Steelsio y reivindicación de su propia obra. En realidad, creo que se impone otra lectura. Como escribe el propio Nucio, algunos años antes había impreso con el Cancionero de romances la colección de romances viejos más grande hasta entonces conocida. Aunque la imagen que en ocasiones se ha intentado ofrecer de este impresor como compilador de romances está más cercana a los modernos colectores de versiones orales que a la labor de un impresor quinientista, no podemos pasar por alto que ya en torno a 1546, cuando aprovecha un pliego suelto para no dejar espacio en blanco en una edición suya de la Questión y cárcel de amor, dispone de materiales romanceriles ${ }^{3}$. Por tanto, puede parecernos algo pretencioso cuando se vanagloria de haber "tomado los años passados el trabajo de juntar todos los Romances viejos", pero no miente. Y tampoco lo hace cuando nota, en el prólogo, que ha "abierto camino a que otros haga $n$ lo mesmo". Me inclino a pensar que con esos otros Nucio no se está refiriendo a Steelsio, ni tampoco a Nájera, quien en

3 Allí, Nucio añade también un pliego suelto al final de la obra, con la siguiente anotación: "Lo que sigue no es de la obra mas puso se aquí porque no vuiesse tanto papel en blanco". Véase A. Askins, V. Infantes y A. RodríGUEZ-MoÑINO 1997, n. 694. 
1550 imprimió, saqueándole su Cancionero de romances, la Silva de romances, ni a ningún otro impresor, sino al propio Lorenzo de Sepúlveda y, con él, a todos aquellos autores, hoy anónimos, que gustaban de los romances viejos y se dedicaban, por las mismas fechas en que Nucio imprime sus obras, a componer romances nuevos y, verosímilmente, a guardar los que recogían. Recordemos lo que Sepúlveda confiesa en su prólogo: que está escribiendo "en tono de Romances viejos que es lo que agora se vsa" (f. 1v). Sí, Nucio dice que la tarea de compilar romances (tarea que, según sabemos, concebía como una actividad de mayores consecuencias para el texto que la mera Niederschrift de los romances ${ }^{4}$ ) la inició él; pero añade inmediatamente que esta empresa no tiene final a la vista, puesto que "cada día se puede añadir, y componer otros de nueuo" (f. 2r; la cursiva es mía). Es entonces, y sólo entonces, cuando Nucio menciona la edición sevillana. Cuando habla del "intento con que esto comencé" está refiriéndose por tanto a una intención editorial propia, coherente, que comienza con el Cancionero de romances y completa con esta compilación de Sepúlveda ${ }^{5}$. Llegados a este punto, la hipótesis que juzgo más probable es, por tanto, que fue Nucio y no Steelsio quien se basó en la princeps sevillana para componer su edición.

Esta hipótesis -que es Nucio, y no Steelsio, quien copia la princeps- no está libre de problemas. Para demostrar su validez hay que solucionar aún varios frentes abiertos. El primero de ellos, el problema de la posible fecha de impresión de la edición de Nucio. Recordemos que a diferencia de la edición de Steelsio, fechada en 1551, la de Nucio carece de fecha de impresión. El bibliógrafo belga Jean Peeters-Fontainas, basándose en los defectos presentes en la marca tipográfica empleada por Nucio en la edición de los romances de Sepúlveda, había propuesto el mismo año de 1551. La marca en cuestión -el conocido escudo de las dos cigüeñas, ya utilizado, entre otras muchas obras, en las dos ediciones del Cancionero de romances- presenta ya tres defectos en esta edición (en la parte inferior izquierda, en la superior y en la derecha) y deja de usarse regularmente en el taller ese mismo año ${ }^{6}$.

${ }^{4}$ Véase Mario Garvin 2007, pp. 165-169.

${ }^{5}$ Cf. M. Garvin 2016.

${ }^{6}$ Véase J. Peeters-Fontainas 1965, p. 27. Resulta muy útil también el monográfico que dedicó a Nucio Jean Peeters-Fontainas 1956. 
Rodríguez-Moñino (1967, p. 26), quien rechaza esta hipótesis de datación, se refiere a la edición de Nucio como "sin año, aunque con toda seguridad [de] hacia 1553", ya que "el taco emblemático pudo usarlo sin dificultad en 1552 ó 1553 o cualquier otro año: bastaría echar mano de él por cuanto andaba por el taller". La observación de Rodríguez-Moñino no es baladí -de hecho, es cierto que Nucio lo emplea una última vez en 1555 , si bien no para una obra en español salida de sus prensas, sino para una obra en francés, de financiación externa al taller ${ }^{7}$, pero sí adolece de un problema, ya que no ofrece argumentos para descartar la hipótesis de Peeters-Fontainas. Sus reticencias no se dirigen contra el método, pues la evidencia de la degradación y el abandono progresivos del taco de madera y su uso para la datación de obras salidas del taller de Nucio había sido ya utilizada por Peeters-Fontainas para fechar el Cancionero de romances. En esta ocasión, Rodríguez-Moñino (1967, p. 26) aceptó la propuesta sin ningún tipo de crítica. Pero aceptarla ahora le parece arriesgado, ya que, como nota, "hay que conceder un cierto tiempo para la preparación del texto con añadidos después que viese Nucio la edición de su colega". Aquí creo que la argumentación de Rodríguez-Moñino se estanca al dar cabida a una asunción innecesaria: que una de las dos ediciones debe depender de la otra, que si Nucio no copió de Steelsio hubo de ser Steelsio quien copiase de Nucio. La dependencia entre ambas ediciones no tiene por qué ser tan directa como se ha venido afirmando.

\section{EDICIÓN PRINCEPS Y EDICIONES PERDIDAS}

Para las disquisiciones siguientes resulta útil partir de la princeps. Es evidente que ni la edición de Steelsio ni la de Nucio son las primeras; en última instancia, por tanto, ambas se remontan a una edición princeps cuyo contenido podemos suponer si nos centramos en las palabras que menciona Sepúlveda en el prólogo. Nos dice allí que "considerando quán provechosa sea la lec-

7 Peeters-Fontainas escribe al respecto: "Une fois encore en 1555, Nutios se sert de cette marque; il imprime, pour compte du libraire Jehan de la Forge, de Tournai, Les Coustumes, Stilz, et Usaiges de l'Esschevinage de la Ville de Tournay. La marque est grossièrement restaurée, du moins telle qu'elle apparait sur la page de titre, alors qu'au dernier feuillet elle se présente avec les trois défauts qui la caractérisaient en 1551” (1956, p. 21). 
tión de historias antiguas", acordó poner "en metro castellano y en tono de Romances viejos, que es lo que agora se vsa", una serie de textos que, según confiesa, "fueron sacados a la letra de la crónica que mandó recopilar el sereníssimo señor rey don Alfonso: que por sus buenas letras y reales desseos y grande erudición... fue llamado el sabio" ". La crónica en cuestión, como bien se sabe, no es otra que Las quatro partes enteras de la Crónica de España, de Florián de Ocampo, publicada en Zamora por Juan de Picardo y Agustín de Paz en 1541, fecha que marca así el terminus ante quem de la princeps. No veo aquí razón para dudar de la sinceridad del autor: si la Crónica ocampiana es la única obra que menciona en el prólogo habrá que concluir que ése es, en efecto, el único texto en el que se basó Sepúlveda para componer sus romances y, con ello, que la princeps de la obra contendría exclusivamente textos sacados de allí.

Podría pensarse, como lo hizo Rodríguez-Moñino (1969, p. 101), que el contenido de la princeps lo obtendríamos prescindiendo de los textos que añaden una y otra edición: "eliminados... los añadidos de la edición s.a. tendremos el texto primitivo que habrá de ser ordenado siguiendo el de Steelsio, una vez suprimido lo que aumentó éste”. Y, sin embargo, tanto la edición de Nucio como la de Steelsio contienen textos que no provienen de la Crónica. En concreto -según los datos de Levey sobre las fuentes de Sepúlveda ${ }^{9}$-, además de los 22 textos que Nucio marca con un asterisco como nuevos, hay en esa edición 37 más que no provendrían de la crónica, textos que, huelga decirlo, se encuentran también en la edición de Steelsio, además de los añadidos de éste. Resumo: si el contenido de la princeps se ceñía a lo prometido por Sepúlveda, sería necesario pensar en la posibilidad de una edición intermedia que añadiera textos a la princeps y que luego, en Nucio y Steelsio, fuera completada con más textos.

Esta hipótesis no es nueva, ya que también Rodríguez-Moñino (1969, p. 103) se preguntaba si no habría habido "un texto primitivo del libro de Sepúlveda limitado a lo que prometía, luego añadido o ampliado en la edición sevillana que sirvió de

8 Cito por la edición de Nucio, según el ejemplar único conservado en la Hispanic Society de Nueva York, ff. 1v-2r.

9 Arthur Edgar Levey 1937. El trabajo es anticuado en muchos aspectos, especialmente en el de las ediciones que utiliza para contrastar los textos. Sin embargo, sigue siendo de utilidad, aunque se echa en falta un estudio más detallado. 
base a Steelsio". Pero las explicaciones del bibliógrafo extremeño respecto a este punto son confusas, pues, aunque por un lado identifica como la princeps ese texto primitivo que se obtendría de eliminar los añadidos de ambas ediciones, según acabamos de ver, por otro plantea la existencia de una edición sevillana que sirvió de base a Steelsio, sin exponer en ningún lugar razones para ello.

A la luz de lo hasta aquí expuesto, parece necesario distinguir entre la princeps -sevillana y ceñida a los materiales que ofrecía la Crónica ocampiana- y una edición intermedia entre la princeps y las dos antuerpienses.

\section{LA EDICIÓN PERDIDA DE NUGIO}

Si creemos en la existencia de esa edición perdida, debemos aceptar que ésta contendría, además de los textos sacados de la Crónica, "una serie de textos que para nada rozan la historia española, otros de tipo exclusivamente religioso y finalmente algunos -no pocos- alejados del marco cronológico que trazó [Sepúlveda]" (Rodríguez-Moñino 1969, p. 103). Con todo, no veo razones para aceptar, como parece dar por sentado Rodríguez-Moñino, que esa edición fuera sevillana. Si la princeps sólo contenía textos de la Crónica, la edición de Nucio no puede estar copiándola directamente, pues comprende textos de otra procedencia. Y, sin embargo, hemos visto más arriba cómo, según dice en el prólogo, Nucio toma un libro impreso en Sevilla. ¿Cómo puede explicarse esta aparente contradicción? Creo, como avanza el titulillo, que hubo, en efecto, una edición intermedia entre la princeps y las conservadas, pero no una edición sevillana, sino una antuerpiense y del propio Nucio.

Varias son las razones que me llevan a ello. La primera se trata de una anomalía. Ya hemos visto que Nucio, en el prólogo, dice que añade al libro sevillano ciertos textos que "van señalados en la tabla con esta señal *" (f. 3r). Sin embargo, de los 22 que Nucio ha marcado como nuevos en la edición conservada, hay uno, El rey amado de Dios, que también aparece en la edición de Steelsio. Para Rodríguez-Moñino no había duda de lo que había ocurrido. Según él, esta composición "aunque se halla en s.a. con * hay que suponer que es por error pues también se encuentra en 1551". No obstante, si afrontamos el problema partiendo de la base de que Nucio no toma el texto 
de Steelsio, sino directamente de la princeps tal y como parecen sugerir sus propias palabras, es posible plantear otra solución.

Al contrario de lo que sucede con la edición de Steelsio, que contiene sin justificación algunos romances que en principio no procederían directamente de la Crónica y se apartarían por tanto del plan original de Sepúlveda, la edición de Nucio añade algunos textos y especifica que se trata de romances "assí de la sagrada escritura como de historias de España” (f. 3r). Ésta no es solamente la temática de los romances añadidos, sino también la de aquellos cuya fuente no hallamos en la Crónica ocampiana. Esos textos son 59 en total (los 22 marcados como nuevos en la edición de Nucio y los 37 de temática ajena a la Crónica que comparten las dos ediciones conservadas). Si analizamos la edición de Nucio desde esta perspectiva, es decir, no como si estuviera añadiendo 22 textos a una base diversa, sino 59 a un grupo homogéneo sacado de una misma fuente, el conjunto cobra mucho más sentido. Incluso el prólogo, leído así, adquiere un nuevo significado, pues la declaración que se hace respecto a la princeps sería literalmente cierta y la advertencia sobre los añadidos se referiría a esos textos comunes a Steelsio y Nucio, cuya procedencia no estaba clara.

Si atendemos al lugar tipográfico de la edición conservada en que Nucio inserta los 22 textos, podremos ver cómo -salvo tres de ellos, que se intercalan en distintos lugares de la obra (A Córdoua está Almançor, f. 23; En prisión estaua el conde, f. 104; Estando sobre Seuilla, f. 157) - se acumulan al final: hay un grupo compacto de 12 textos que se extiende del f. 208 al f. 221 (del romance La mañana de Sant Juan a Yo me estaua en vna fiesta); Cartago florece en armas, en el f. 234; 5 romances que van del f. 251 al f. 259 (El rey amado de Dios, Muy moço era Salomón, Vn hijo del rey Dauid, Muy triste fue el rey Dauidy Absalón después de aquesto); y, finalmente, Grande monarcha era Assuero, que cierra el volumen en el f. 269.

Significativamente, éstos son también los lugares tipográficos en que aparecen los textos que suponemos añadidos de Nucio a la princeps, es decir, aquellos que no procederían de la Crónica de Ocampo ni serían por tanto romances compuestos por Sepúlveda. Así, cuando Nucio añade 22 textos parece estar siguiendo un plan establecido, pues los inserta junto a romances de temática semejante. Mi hipótesis es que ese plan determinó el orden de una primera edición antuerpiense del propio Nucio, que habría añadido textos a la princeps sevillana. Luego, 
en una segunda edición, incorporaría más composiciones (los 22 marcados con asterisco), pero siguiendo el plan que él mismo había fijado en la edición anterior. Entonces, si consideramos que El rey amado de Dios sería un añadido de la segunda edición, tendríamos con él un bloque de 5 romances que arriba he enumerado, los cuales aparecen entre el f. 251 y el f. 259. Estos textos, que se intercalan en un grupo mayor de 11 romances de temática ajena a la Crónica, serían añadidos, por tanto, de la primera edición de Nucio a la princeps. El resultado es el siguiente:

Súbditos son los de Athenas
Los galos entran por roma
Llanto haze dolorido
Porsena rey poderoso
En la alta Veracruz
El gran Nabucodonosor
Gran guerra tiene Saúl
El rey amado de Dios (*)
Muy mozo era Salomón*
Un hijo del rey Dauid*
Muy triste fue el rey Dauid*
Absalón después de aquesto*
Orán que era rey de Hebrón
El sancto san Juan Bautista
En León la muy nombrada
En un valle muy obscuro

Probablemente, el error que cometieron los operarios del taller fue marcar ese texto con asterisco, cuando en realidad ya estaba en la primera edición. O, dicho de otro modo, dejar la marca que el texto llevaría en la edición perdida. Marcar 4 textos nuevos dentro de un grupo que también había sido marcado como tal en la edición anterior, puede provocar descuidos, como dejar asteriscos al lado de composiciones que no forman parte del repertorio inédito. Sin embargo, me parece que se trata de un error verosímil, más aún cuando en el índice de Nucio el verso aparece, además, con una errata (El rey amado dios*), que refuerza esa hipótesis de que el asterisco no es más que un descuido que se comete al aumentar la edición en el taller. Es muy probable incluso que en su nueva edición -la conservada- Nucio ni siquiera cambiase el prólogo de la anterior, la 
cual damos por supuesta, ya que las afirmaciones relativas a la temática de los textos y al hecho de que fueran añadidos seguían teniendo validez, si bien se referían ahora a otros romances. Ésta es, de hecho, una práctica nada extraña: el propio Nucio repetirá el prólogo de la edición de 1550 del Cancionero de romances en la de 1555 sin cambiar una sola palabra.

Hay otros aspectos que refuerzan mi suposición de que Nucio, en la edición conservada, está siguiendo un plan anterior que él mismo había trazado. Nucio, en el prólogo, dice haber modificado el orden de los romances -que en la princeps se ajustarían probablemente al de la Crónica- para que se lean "no como estauan sino como deuen". Se trata exactamente del mismo modo de proceder que ya hubiera sido ensayado por el propio Nucio en el Cancionero de romances. Como he escrito en otro trabajo:

En el que constituye el primer intento de ordenación sistemática del romancero, Nucio, disculpándose de nuevo por la "mezcla de unos y otros" que pudiese haber quedado, distribuye los romances poniendo "primero los que hablan de cosas de Francia y de los doze pares después los que cuentan historias castellanas y después los de troya y últimamente los que tratan cosas de amores". En los pliegos sueltos... el orden y aun la selección de los textos podía hacerse en función de un mensaje supratextual más o menos meditado; en casos como este, en el que el número de romances es superior a 150 , tal empresa estaba destinada al fracaso. Quedaba sólo la posibilidad de ordenarlos en función de la historia que narraban (M. Garvin 2007, p. 168).

Esa narratividad perseguida por Nucio, visible de igual modo en las adiciones a la edición de 1550 del Cancionero de romances, es la que también busca en la reordenación de los Romances de Sepúlveda y justificaría en parte los romances añadidos y el lugar que ocupan. Alejandro Higashi, quien se ha ocupado del problema del orden en las ediciones de Lorenzo de Sepúlveda, escribe:

A Sepúlveda no le interesaba contar una historia completa a partir de una retacería de partes, tarea editorial que había sido ya emprendida y resuelta, sino añadir al corpus romanceril aquellas secuencias narrativas que no habían sido contadas ya. Como valor de cambio, lo que ofrecía Sepúlveda eran nuevas historias que vinieran a complementar la experiencia del romancero en 
el pliego suelto y en la reciente compilación de Martín Nucio, tan íntimamente imbricadas. La unidad en la que piensa no es el libro y mucho menos el pliego suelto, sino el romancero impreso en su totalidad (2015, p. 632).

Estoy completamente de acuerdo con esta apreciación, a la que haría, no obstante, una precisión fundamental: creo que Higashi se equivoca al atribuir la responsabilidad de la selección a Sepúlveda. Al describir la labor del autor, el estudioso señala:

Luego de identificar un episodio (o una serie de episodios) que pueden resultar atractivos para volverlos romances... y comprobar que no habían sido recogidos por los pliegos sueltos (y consecuentemente tampoco por... Martín Nucio, en el Cancionero de romances de 1547-48) Lorenzo de Sepúlveda iniciaba el proceso de redacción (p. 630).

Es indiscutible que Sepúlveda era un buen conocedor del romancero, tan en boga por aquellos años; sin embargo, atribuirle un conocimiento tal del mercado editorial como para elegir los temas que romancea en función de los vacíos que hubiera dejado el Cancionero de romances, me parece exagerado. Además, hay que tener en cuenta que Higashi parte de los textos contenidos en la edición de Steelsio. Sepúlveda, según hemos visto, romancearía solamente la Crónica ocampiana. Pero el plan descrito por Higashi es rastreable también en textos que no tienen esa procedencia, es decir, en textos que suponemos añadidos por Nucio a la princeps. En otras palabras: el plan existe, pero no parece obra de Sepúlveda. Y es que por aquellos años solamente una persona tenía tal conocimiento del mercado de los romances y pliegos sueltos, a la par que la intuición editorial necesaria para llevar a cabo esa tarea: el propio Nucio. ¿Quién mejor que él -teniéndolo, claro está, por cabeza visible de un negocio editorial compuesto por varias personas- para entender qué romances podían completar su Cancionero? ¿Quién más preparado para completar una colección que encajaba de maravilla en su proyecto editorial? Me temo que, en este caso, la admirable intuición de Higashi se ve lastrada por aceptar la dependencia entre las ediciones postulada por Rodríguez-Moñino. Al hacerlo, interpreta con él que Steelsio reproduce de manera más o menos fiel la edición sevillana y que Nucio sigue a Steelsio. Desde esa perspectiva hay, según él, dos actividades: por un 
lado, la de ofrecer una serie de textos que cubriera los espacios narrativos que dejaban los pliegos sueltos y, consecuentemente, el Cancionero de romances, actitud que Higashi atribuye a Sepúlveda; por otro, la de ordenar esos textos de un modo coherente según la concepción narrativa iniciada con el Cancionero de romances, que atribuye a Nucio, quien según Higashi trabajaría con el propósito de "restaurar para el lector un orden más convencional" (p. 633). En realidad, parece más lógico creer que ambas tareas son las dos caras de una misma moneda y que sería el propio Nucio quien ordenó los textos y también quien completó con ello un plan narrativo que él mismo había delineado.

Resulta útil pensar ahora en la posible fecha de impresión de esta primera edición antuerpiense. Ya hemos mencionado que en el prólogo Nucio se refiere al Cancionero de romances y que la edición conservada, por tanto, debía ser necesariamente posterior a él. Esta afirmación, desde luego, vale sobre todo para la primera edición perdida, que aparecería en torno a 1549 o, como muy tarde, a principios de 1550 , anterior en cualquier caso a la edición del Cancionero de romances de ese año. Nucio había logrado reunir para el Cancionero de romances la nada despreciable cifra de 156 textos, que luego aumentaría a 185 en la edición de 1550. Seguramente, atento como estaba al mercado nacional, en contacto permanente con ferias y mercaderes, Nucio no pasaría por alto que por aquellas fechas ya se componían romances nuevos y, en consecuencia, comenzaría a reunirlos. Naturalmente, ni los que logró encontrar ni la princeps de Sepúlveda le parecieron ofrecer número suficiente de textos, así que unió los unos a los otros hasta conseguir 162 y ofrecer de esta manera un volumen tipográficamente idéntico al que había sacado al mercado poco tiempo atrás: un dozavo de $275+1$ páginas, dato que no puede ser casual sino que responde, como intento demostrar en otro trabajo (Garvin 2016), a una práctica editorial común en Nucio, evidenciada tanto en el Cancionero de romances como en los Romances de Lorenzo de Sepúlveda.

\section{LA FUente de STEelsio}

Esta edición perdida de Nucio sería así la fuente en la que se basó Steelsio para su propia edición. Partiendo de esta hipótesis, se puede resolver gran parte de los problemas que surgen al comparar las ediciones antuerpienses conservadas. Pensemos, por 
ejemplo, en el caso del romance El rey amado de Dios, que aparece en ambas ediciones pese a que Nucio lo marca como nuevo. $\mathrm{Si}$, como hemos apuntado, ese romance estuviera ya en la edición perdida de Nucio, su presencia en Steelsio se entendería mejor; no en vano estos textos presentan aquí exactamente el mismo orden que suponemos para la primera edición de Nucio:

\section{En la alta vera cruz \\ El gran Nabucodonosor \\ Gran guerra tiene Saúl \\ El rey amado de Dios \\ Orán que era rey de Hebrón}

No es éste el único ejemplo en favor de nuestra hipótesis acerca de que Steelsio se basó en una edición perdida de Nucio. Uno de los romances que no procede de la Crónica de Ocampo y aparece en ambas ediciones es el de la duquesa de Loreyna, En la ciudad de Toledo, que ya había aparecido en el Cancionero de romances s.a. Rodríguez-Moñino (1967, p. 16) se da cuenta de ello, pero se limita a anotar, sin dar explicación alguna, que "En la ciudad de Toledo figura en el Cancionero de romances s. $a$. y probablemente Nucio y Steelsio lo tomaron independientemente de una fuente común, acaso de un pliego suelto hoy perdido". Como sabemos, las fuentes principales de Nucio para el Cancionero de romances fueron los pliegos sueltos (Garvin 2016a). Parece muy improbable, conociendo las costumbres editoriales de Nucio, que disponiendo de ese texto acudiera de nuevo a otras fuentes, más aún cuando las ediciones posteriores del Cancionero de romances no muestran -a diferencia de lo que ocurre con otros textos- que Nucio considerara defectuosa la versión de la edición sin año. Sin embargo, una comparación detenida de los textos revela que el de Steelsio es más cercano en muchos casos al de las dos ediciones del Cancionero de romances (N47), que no a la edición de Nucio conservada de los Romances de Sepúlveda. De hecho, Steelsio (SES) sigue a N47 incluso en ciertas particularidades ortográficas (vv. 61, 144 o 184, por ejemplo), y es la edición antuerpiense de Nucio (SEN) la que ofrece lecciones divergentes. Sirvan estos ejemplos ${ }^{10}$ :

${ }^{10}$ N47 = Cancionero de romances s.a.; N50 = Cancionero de romances, 1550; $S E S=$ Sepúlveda, ed. Steelsio, 1551; SEN = Sepúlveda, ed. Nucio. 


31 fueron se al emperador
32 y cada vno dezía
59 que osassen a combatirse
61 assí partió para España
94 y mucha gente los mira
120 sin conoscer mejoría
144 mis golpes él sintiría
149 y vase contra lembrot
153 pues Almeric y Agreses
182 a Lembrot del yelmo tira
184 la cara le descobría

La cercanía textual de Steelsio a los estados del Cancionero de romances es evidente, y resulta lógico, según hemos dicho, pensar que Nucio, a la hora de incorporar ese texto en su edición, recurrió a los propios materiales, es decir, que Nucio, para la primera edición de los romances de Sepúlveda que le suponemos, se valió de sus propios textos. De este modo, cabe suponer que Steelsio se estaría sirviendo de una edición anterior de Nucio, lo que explicaría su cercanía textual a la edición sin año del Cancionero de romances. ¿Cómo explicar, no obstante, las divergencias de Nucio respecto de su propio texto? Hay para ello varios motivos. Hay que apuntar que se trata, básicamente, de erratas y leves variantes, que en ningún caso representan modificaciones sustanciales. Dicho esto, no podemos pasar por alto que las reediciones de Nucio -lo vemos perfectamente en el Cancionero de romances-no se limitan a copiar los textos a plana y renglón, sino que se someten a correcciones. Muchas de estas variantes tienen todos los visos de ser erratas de manual; otras, en cambio, coinciden con correcciones que presentan las ediciones de 1555 y 1568 del Cancionero de romances; pienso en concreto en la variante del verso 144 :

mis golpes él sintiría $N 47, N 50$, SES él sentiría $S E N$ bien sentiría N55 N68.

Estos datos parecen sustentar la existencia de una edición perdida, que serviría de base a Steelsio y que Nucio, al reeditar, corregiría; de ahí ciertas variantes. Por lo demás, no podemos descuidar que cada edición es una obra particular y que en su composición surgen particularidades tipográficas que pueden condicionar el texto. Así, en este mismo romance de la Duque- 
sa de Loreyna, la variante más clara, tal vez la que hizo pensar a Rodríguez-Moñino en la existencia de dos fuentes distintas, es la del título. En él, Steelsio lee con el Cancionero de romances:

ROMANCE DE LA DVqucsa dc Loreyna sacado de ls historia dcl rcy don Rodrigo que perdió a España N50, SES (N47: Hespaña).

Mientras que la edición de Nucio ofrece un título más largo:

Romance de la venida que la duquesa de Lorena hizo a la corte del rey don Rodrigo a pedir quién la favoresciesse sobre cierto repto que le fue hecho como Sacarus se le ofeció SEN.

La razón, sin embargo, no radica en la fuente utilizada, sino exclusivamente en la posición tipográfica del título, que en esta edición de Nucio aparece en el f. 205r, justo en el primero de la signatura $\mathrm{S}$, a fin de cerrar página y de que el romance pueda comenzar con el primer verso en la página siguiente. Se trata, por tanto, de una ampliación artificial, hecha en el taller por necesidades específicas.

Esta tendencia y suposición que venimos apuntando acerca de la fuente de Steelsio se confirma en otros ejemplos. Una prueba muy contundente la hallamos, creo, en el romance del Conde Fernán González, que comienza "El rey don Sancho Ordoñes". El romance, de 116 versos, se extiende en la edición de Nucio del f. 97v al f. 99r, mientras que en la de Steelsio, del f. $63 \mathrm{v}$ al f. 65v. La edición de Nucio presenta, sin embargo, una particularidad: los versos 37-63 y 64-88 aparecen en el orden inverso al que tienen en la edición de Steelsio, que presenta la disposición correcta (o, al menos, la única que confiere sentido al romance). Es posible, desde luego, que Steelsio copiara el romance de la edición conservada de Nucio, advirtiera el error y lo subsanara, pero, como ya hemos visto en las páginas anteriores, hay motivos suficientes para concluir que Steelsio no siguió esta edición, como tampoco Nucio la de Steelsio. Éste es probablemente el caso -a nivel textual- que más claramente lo demuestre. Estamos hablando de dos tiradas de 26 versos, cada una colocada en el orden inverso, de manera que el romance en la edición de Nucio se lee 1-37; 64-88; 38-63 y 89-116, disposición que carece por completo de sentido. Este tipo de errores suele producirse durante la fase de composición, especialmente cuando el original que se emplea en la imprenta (y en este 
caso debemos suponer que ese original era un impreso) tiene versos en lugares problemáticos, como son el cambio de página, de cuaderno, etc. o, lo que aquí es mucho más probable, cuando se insertan añadidos a un original -como hemos visto que sucede en la edición de Nucio-, ya que entonces el original debe contarse de nuevo. Es ahí, posiblemente, donde se originó el error con el que nos enfrentamos. De hecho, en la edición de Nucio, el romance en cuestión se localiza en el cuaderno I, precisamente donde se intercala uno de los textos añadidos a esta edición: En prisión estaba el conde, que aparece en ff. 104r y $104 \mathrm{v}$, ocupando 28 versos en el recto y 22 en el vuelto. No debe descartarse, pese a lo complejo de realizar estos cálculos, que el error del que hablamos fuese el resultado de esa operación. Steelsio, en cambio, presenta el orden correcto, ya que toma el romance de la edición anterior.

Hasta aquí parece demostrado que las dos ediciones antuerpienses conservadas, la de Nucio y la de Steelsio, proceden de una edición antuerpiense perdida, publicada por Nucio en torno a 1549 o 1550, que reproduciría una edición princeps sevillana, reordenada y con añadidos. Sin embargo, todavía quedan dos puntos que aclarar; primero, determinar el tipo de relación que hay entre las dos ediciones conservadas y, luego, ver si esta relación permite explicar el orden de la edición de Steelsio.

\section{¿EDICIÓN COMO REACCIÓN?}

$\mathrm{Al}$ intentar determinar la relación entre las ediciones conservadas de Nucio y Steelsio creo que puede descartarse por completo que alguno de estos dos impresores actuase sin tener noticia de las actividades del otro. Debemos suponer, pues, que el último en sacar a la luz pública su edición, lo hizo con conocimiento de la precedente. Partiendo de esta premisa, creo que varios factores apoyan la idea de que la edición de Nucio apareció después de la de Steelsio. Si este impresor, en 1551, hubiera decidido publicar una nueva edición de los romances de Sepúlveda, la de Nucio, que sería casi paralela, hubiese carecido por completo de sentido, pese a la nueva ordenación y a los añadidos. En cambio, si la primera edición de Nucio sirvió de patrón para la de Steelsio, la segunda de Nucio podría interpretarse como una reacción a la de quien lo ha emulado y, con ello, como un intento de restablecer su primacía. A favor de esta tesis habla el 
pocas veces mencionado privilegio que campea en la portada de la edición de Nucio, la cual, de haber sido anterior, habría frustrado la de Steelsio.

Esta relación entra por completo dentro de la lógica editorial. Rodríguez-Moñino-independientemente de la posibilidad de una edición precedente- dudaba de la fecha de 1551 propuesta por Peeters-Fontainas para la edición de Nucio, porque no creía que implicara el tiempo suficiente para preparar una edición basada en otra anterior. Tengamos en cuenta, no obstante, que el taller de Nucio estaba en condiciones de imprimir con notable celeridad. Desconocemos, por desgracia, el número de operarios y prensas de que disponía, pero sí sabemos, por ejemplo, que en 1555 logró sacar al mercado, en sólo cuatro meses, dos traducciones de Erasmo del humanista Bernardo Pérez: Silenios de Alcibiades y Preparación y aparejo para bien morir ${ }^{11}$. El taller de Nucio, por tanto, era perfectamente capaz de editar una obra de las características de los Romances de Sepúlveda en el mismo año de 1551 en que había aparecido la edición de Steelsio, incluso muy poco después. No podemos pasar por alto que estaríamos hablando de una obra relativamente sencilla de componer, sobre todo porque para trasladar el texto versificado de un original impreso a la caja, solamente hay que contar cuántos versos caben en una página. Los añadidos de la edición no suponen un problema adicional, menos aún en este caso, en que las incorporaciones se acumulan en los cuadernos finales del tomo, los cuales se pueden ir preparando mientras que se componen e imprimen los primeros. Que Nucio imprimió con prisas puede constatarse al advertir el texto de los romances. El caso ya mencionado del romance con dos series de 26 versos invertidos es quizá el más evidente, pero no el único, pues a lo largo de todas las páginas de la edición encontramos repartidas numerosas erratas.

A Nucio no le bastaría con sacar rápido su edición; debía de ofrecer, además, algún tipo de novedad y atractivo que superaran la edición de Steelsio, ya en el mercado, e incluso la que él mismo había publicado anteriormente. A esta necesidad responden los textos añadidos y también, según creo, la fórmula que se usa para anunciarlos. En el prólogo, Nucio dice que hizo "añadir otros muchos" para, acto seguido, informar que "el

11 Peeters-Fontainas 1965, nn. 382 y 388. Véase Josep Lluís Martos 2015, p. 84, n. 27. 
nombre del autor de los añadidos se calla porque se guarda para cosas mayores que conformen con su persona y hábito". Lo único que se menciona de tal autor, y en la portada, es que se trata de un "cauallero Cesario, cuyo nombre se guarda para mayores cosas", y de sus romances, que son inéditos: "nu nca vistos". Menéndez Pelayo supuso que este caballero, "amigo" de Sepúlveda, sería Pero Mexía, atribución que aceptaron muchos otros, como Menéndez Pidal, pero de la cual sospechó Rodríguez-Moñino. De hecho, no creo en lo absoluto que los añadidos sean todos obra de un solo autor. Más bien parece que la anonimia es un recurso que empleó Nucio para cubrir sus textos con un velo de misterio que despertara el interés por quien pudiera ser ese caballero, quizá conocido entre los círculos cortesanos, o al menos para desatar en ellos la especulación al respecto. No olvidemos, como ha consignado Josep Lluís Martos (2010, p. 119), que también en la edición de 1557 del Cancionero general aparecen ciertas composiciones anónimas que Nucio atribuye a "dos cavalleros cuyos nombres se dexan para mayores cosas, con ciertas obras de otro autor cuyo nombre también se reserva. P.P.D.A.R.A." Por tanto, continúa Martos, "aunque parezca lógico que el anonimato de los poetas haya sido obra de los mismos autores o del copista del cancionero, no creo que debamos descartar la intervención de Martín Nucio".

La segunda edición de Nucio persigue entonces un doble objetivo. Busca, en principio, completar el plan editorial comenzado en la primera. Creo necesario remarcar aquí que dentro de este plan el papel que desempeña Lorenzo de Sepúlveda es secundario. La princeps sevillana ofrece a Nucio la base principal sobre la que construir su edición, pero lo que realmente le interesa al reordenar y añadir textos a la princeps es ofrecer una colección que complete la anterior, el Cancionero de romances. En Garvin 2016 (pp. 565-568) he defendido que la primera edición del Cancionero de romances surgió motivada por un hecho histórico concreto, el felicísimo viaje del futuro Felipe II, de lo que esa primera edición hoy perdida también sería parte. Del mismo modo, la edición antuerpiense conservada debe entenderse como componente de un segundo proyecto del que también forma parte la edición de 1550 del Cancionero de romances. Pero la segunda edición, además, entra en competencia más o menos directa con la de Steelsio. Este dato puede ayudarnos, creo, a comprender la última pieza de este rompecabezas: el orden de la edición de Steelsio. 


\section{EL ORDEN DE STEELSIO}

Ya hemos señalado que Steelsio estaría copiando una edición perdida de Nucio. Puesto que Nucio en la edición conservada, según hemos intentado demostrar, estaría siguiendo el plan trazado en su primera edición, no resulta aventurado conjeturar que esa edición perdida presentaba el mismo orden de los textos que la conservada, salvando obviamente los anadidos y el romance Atanagildo rey godo, que fue colocado en esta última "fuera de la orden porque el papel no quedase blanco" (ed. Nucio, f. 6r), pero que en la edición perdida obviamente ocuparía otra posición ${ }^{12}$.

La edición de Steelsio presenta por tanto un orden notablemente distinto al de su fuente. Según Alejandro Higashi (2015, p. 633), la edición de Steelsio propone "una alternativa al modelo de edición seguido por los pliegos sueltos y por Nucio", aunque creemos que también aquí se equivoca al hablar de "el cancionero de Sepúlveda", pues en realidad el autor sevillano nada tuvo que ver con la ordenación propuesta por Steelsio. La diferencia no es baladí: si la propuesta de ordenación fuera de Sepúlveda, Steelsio se habría limitado a reproducir de modo más o menos fiel la intención autorial de la princeps; si el orden, sin embargo, lo atribuimos al propio Steelsio (que estaría modificando el orden de la edición que copia: la de Nucio), nos las habemos con un modelo editorial alternativo al propuesto por su fuente, y esto es importantísimo, porque nos explica la divergente organización de los romances y, a la postre, confirma la relación entre ambas ediciones antuerpienses que acabamos de proponer.

Hablando de la edición de Steelsio, Higashi (2015, p. 634) observa que "parece estar organizad[a] en torno a dos paradigmas: el guerrero hispano matamoros que sale victorioso en las batallas (figura a la que de forma muy ad hoc se une Rodrigo Díaz) y las peleas entre nobles". Siguiendo esta idea, Higashi muestra de forma convincente cómo las primeras cien páginas se organizan en torno a estos dos núcleos. Que Steelsio no siempre lo logre es, sin duda, a causa de algunos textos, los añadidos

${ }^{12}$ A no ser, claro está, de que el hueco en blanco se originase ya en la primera edición y, simplemente, se mantuviera allí en las siguientes ediciones, como ocurre, por ejemplo, en la edición de 1563, que aún conserva este lugar particular. 
por Nucio en la primera edición, que imponen precisamente esa narratividad de la que Steelsio busca escapar. Y, sin embargo, ahí está la clave del nuevo orden: ofrecer una alternativa a los romances de Nucio. No puede ser casual que, en la edición de Steelsio, los romances añadidos por Nucio a la princeps, ocupen, casi infedectiblemente, toda la segunda mitad de la obra, mientras la primera se nutre casi exclusivamente de aquellos textos que provendrían de Lorenzo de Sepúlveda. De los textos añadidos, sólo cinco aparecen antes de la página 134 y el resto se concentra en el final. Esto muestra que Steelsio solamente podía proponer un modelo alternativo al ideado por Nucio con aquellos textos que no eran añadidos de éste. Merece la pena recordar aquí que Nucio organiza los romances en secuencias narrativas. Aquellos textos, como los de Sepúlveda, que tenían desde un principio otro orden, pueden "reorganizarse"; los que Nucio añade con ese propósito, sin embargo, son mucho más difíciles de colocar, pues cualquier cambio los aleja de su función.

Esto explica el porqué de la edición de Steelsio, su motivación editorial. Ya se ha mencionado la rivalidad entre ambos impresores, que les llevó, como recordó Rodríguez-Moñino, a editar la misma obra en varias ocasiones. Ocurrió, por ejemplo, con los Apotegmas de Erasmo, que ambos editaron en 1549: Nucio tomó la versión de Francisco de Thámara y Steelsio la de Juan de Jarava ${ }^{13}$. Pero Steelsio no vio los Romances de Sepúlveda como ocasión para el desquite, según consideraba RodríguezMoñino; no pudieron serlo, ya que fue Nucio quien reeditó en Amberes la princeps (¿recién?) llegada de Sevilla. Con esa primera edición antuerpiense, Nucio daba continuidad a la genial idea editorial, iniciada con el Cancionero de romances, de ofrecer en volúmenes una compilación exhaustiva. Al tiempo, sin embargo, espoleado quizá por la aparición en 1550 de la segunda edición del Cancionero de romances, prueba patente del éxito de la idea de su competidor, Steelsio acometería la única empresa que garantizaba salida: si no podía ofrecer textos distintos, al menos los ofrecería de modo distinto.

En otro trabajo, Alejandro Higashi (2015a, pp. 85-86) ha recordado que "una iniciativa editorial satisface una demanda latente y, como consecuencia del impacto logrado en el consumidor, genera una ola de proyectos que buscan instalarse en la estela del éxito comercial que les precede mediante la imitación", así

13 Sobre esto, véase Peeters-Fontainas 1965, nn. 386 y 387. 
como que "el mayor reto consiste, por supuesto, en mantener las características que dieron éxito a la fórmula del modelo, pero con alguna novedad frente al consumidor que confiera cierta ventaja a los recién llegados". Steelsio ensayó esa novedad por dos vías. La primera, ya lo hemos visto, fue organizar un conjunto de romances en una estructura supratextual novedosa, que ofreciera al lector un modo distinto de leer los textos. La segunda, acompañar ese corpus con otras composiciones que subrayasen la novedad del proyecto; así se observa, por ejemplo, cuando la edición de Steelsio informa en la portada que "añadiose el Romance de la conquista de la ciudad de África en Beruería, en el año M.D.L. y otros diuersos, como por la Tabla parece".

Lo que en muchos otros impresores es una mera técnica para evitar papel en blanco -lo hemos observado en Nucio, quien a su vez ya lo había hecho en su edición de la Questión de amor de 1546- es en Steelsio (también) un mecanismo propagandístico para publicitar su edición. El romance que se añade es un pliego suelto completo ${ }^{14}$, el cual conserva incluso su portada, que ya había sido impreso por Steelsio el año anterior a su edición, en 1550. Tipográficamente, el romance se encuadra en un conjunto de textos que ocupa los últimos cuadernos del volumen y que cumple, creo, esa doble función de servir, por un lado, de relleno tipográfico -es conocido el empeño de los impresores quinientistas en ofrecer al lector volúmenes con un número redondo de cuadernos sin que haya en ellos hojas vacías- y, por otro, de reclamo de novedad. Se incluyen en este grupo, además del mencionado, los romances $A$ los alpes y altas sierras, En los tiempos que me vi, Esperança me despide y La bella malmaridada, así como unas coplas de Pero Mexía (Vna ley establecía), un Iuyzio que echó un moro lamentando la pérdida que esperaua de Valencia, en prosa, y la composición Aunque me falte osadía, titulada erróneamente como romance. El éxito de su propuesta, sin embargo, fue breve. Nucio publicó muy poco después su reedición, que sería la única hasta que, ya en la década siguiente, aparecieran en la península nuevas ediciones, segura la de Alcalá en 1563, probable la de Medina de $1562^{15}$, para arrancar, a partir de ahí, una nueva andadura editorial. El romancero erudito necesitó más de una década para comenzar a asentarse editorialmente. Esperamos haber contribuido a comprender sus bases.

14 Cf. A. Askins, V. Infantes y A. Rodríguez-Moñino 1997, n. 1056bis.

15 Cf. A. Rodríguez-MoÑino 1967, p. 30. 


\section{REFERENCIAS}

Askins, A., V. Infantes y A. Rodríguez-Moñino 1997. Nuevo Diccionario bibliográfico de pliegos sueltos poéticos, Castalia, Madrid.

Cancionero de romances s. a. Martín Nucio, Amberes.

Garvin, Mario 2007. Scripta manent. Hacia una edición crítica del romancero impreso. (Siglo XVI), Iberoamericana, Madrid-Frankfurt/M.

Garvin, Mario 2016. "Edición e intención editorial: los romances de Martín Nucio", Lemir, 20, pp. 561-576.

Garvin, Mario 2016a. "Martín Nucio y las fuentes del Cancionero de Romances", eHumanista, 32, pp. 288-302.

Higashi, Alejandro 2015. "El Cancionero de romances como paradigma editorial”, Boletín de la Real Academia Española, 95, pp. 87-117.

Higashi, Alejandro 2015a. "Imprenta y narración: articulaciones narrativas del romancero impreso", en Literatura y ficción. "Estorias", aventuras y poesía en la Edad Media. Ed. Marta Haro Cortés, Universitat de València, València, t. 2, pp. 627-641.

Levey, ArThur Edgar 1937. The sources of the ballads by Lorenzo de Sepúlveda, University of Chicago, Chicago.

Martos, Josep Lluís 2010. "El público de Martín Nucio: del Cancionero de romances al Cancionero general de 1557", en Convivio: cancioneros peninsulares. Eds. V. Beltrán y J. Paredes, Universidad de Granada, Granada, pp. 111-123.

Martos, Josep Lluís 2015. "Juan Martín Cordero en Flandes: Humanismo, mecenazgo e imprenta”, Revista de Filología Española, 95, 1, pp. 75-96.

Menéndez Pelayo, Marcelino 1944. Antología de poetas líricos castellanos. (Edición nacional), CSIC, Madrid.

Menéndez Pidal, Ramón 1953. Romancero hispánico (hispano-portugués, americano y sefardi). Teoría e historia, Espasa Calpe, Madrid.

Peeters-Fontainas, Jean 1956. L'officine espagnole de Martin Nutius à Anvers, Société des Bibliophiles Anversois, Amberes.

Peeters-Fontainas, Jean 1965. Bibliographie des impressions espagnoles des PaysBas méridionaux, De Graaf, Nieuwkoop.

Rodríguez-Moñino, Antonio 1967. Lorenzo de Sepúlveda. Cancionero de romances (Sevilla, 1584), Castalia, Madrid.

Rodríguez-Moñino, Antonio 1969. La Silva de romances de Barcelona, 1561. Contribución al estudio bibliográfico del romancero español en el siglo XVI, Universidad de Salamanca, Salamanca.

SEPÚlvedA, LORENZO DE 1903 [1551]. Romances nueuamente sacados de historias antiguas dela crónica de España compuestos por Lorenço de Sepúlveda. Añadiose el Romance dela conquista dela ciudad de África en Beruería, enel año M.D.L. y otros diuersos, como por la Tabla parece. En Anuers, en casa de Iuan Steelsio, Archer M. Huntington, De Vinne Press, New York. 